\title{
OS DIREITOS DOS POVOS DE TERREIRO NA ENCRUZILHADA: O USO DO ATABAQUE E O MEIO AMBIENTE.
}

\author{
Andréa Letícia Carvalho Guimarães ${ }^{1}$ \\ DOI 10.26512/revistacalundu.v3i2.28958
}

Os direitos dos povos de terreiro ao longo da história brasileira encontram-se na encruzilhada, ou seja, estão sempre sendo colocados em ameaça pelas concepções hegemônicas da sociedade, que tentam impor a sua compreensão de mundo como a única verdade. Por isso, o que lhe parece "diferente" acaba sofrendo retaliações e mesmo na égide do Estado Democrático de Direito, essas comunidades têm seus direitos cotidianamente violados, tendo que lutar por reconhecimento e visibilidade para que os seus conhecimentos ancestrais não desapareçam.

Essa situação de luta contínua aparece na diáspora africana e reverbera até os dias atuais (HALL, 2003). O Estado brasileiro, diante de várias casos que mencionaremos nesta nota, que os povos de terreiro/ religiões afro-brasileiras, com seus atabaques causam "perturbação do sossego" e "poluição sonora", sobre essa alegação várias casas do Brasil estão sendo fechadas, ora porque são multadas em valores altíssimos, ora porque são exigidas adaptações das casas impossíveis para essas comunidades, como, por exemplo, isolamento acústico.

Além do notório racismo religioso ${ }^{2}$ que reveste tais práticas, em muitos dos casos não há a medição dos decibéis para comprovação das acusações e a abordagem policial e dos agentes públicos ocorre de forma violenta, simplesmente interrompendo os cultos e apreendendo os atabaques. Há imposição de multas altíssimas, não permitindo ao menos que as casas se defendam, quando não impõe a adequação dos cultos a isolamento acústico.

\footnotetext{
${ }^{1}$ Mestra em Direito pela Universidade de Brasília (UnB). Advogada e professora de Direitos Humanos. Pesquisadora do Centro Cultural Orè (CECORÉ) e do grupo CALUNDU.

${ }^{2} \mathrm{O}$ que se ataca é precisamente a origem negra africana destas religiões. Por isso, vejo uma estratégia racista em demonizar as 'religiões' de matrizes africanas, fazendo com que elas apareçam como o grande inimigo a ser combatido, não apenas com o proselitismo nas palavras, mas também com ataques aos templos e, mesmo, à integridade física e à vida dos participantes destas 'religiões'. Portanto, isso que visualizamos sob a forma da intolerância religiosa nada mais é que uma faceta do pensamento e prática racistas que podemos chamar de racismo religioso (NASCIMENTO, 2016, p. 168, grifo do autor).
} 
Essa situação ocorreu no município brasileiro de Florianópolis, em Santa Catarina. O Fórum das Religiões de Matriz Africana de Florianópolis denunciou à Defensoria Pública da União uma série de ataques perpetrados pelo Estado contra as atividades religiosas e contra os templos afro-brasileiros, a saber, terreiros, casa de candomblé, batuques e centros espíritas de Umbanda, dentro do Município de Florianópolis (BRASIL, 2017).

O Poder Público Municipal negava o reconhecimento aos terreiros como espaços de culto religiosos, como espaços sagrados, constitucionalmente protegidos. $\mathrm{Na}$ realidade, consideravam como "comércio em geral", cobrando o cumprimento de uma série de exigências, que acabavam por impedir a livre manifestação religiosa das casas afro-religiosas. Para tanto, utilizavam como fundamento a Lei Complementar Municipal nº 003/99 (BRASIL, 2015) para inviabilizar realização das cerimônias.

Os órgãos municipais e também a Fundação do Meio Ambiente conjuntamente com a Polícia Militar do Estado de Santa Catarina, aplicavam multas, penalidades e faziam cessar as atividades religiosas/culturais, agredindo a comunidade afro-brasileira.

Em razão dessa situação, a Defensoria Pública da União ingressou com uma ação civil pública contra à União, o Estado de Santa Catarina, o Município de Florianópolis, a Fundação do Meio Ambiente (FATMA), Fundação Municipal de Meio Ambiente de Florianópolis (FLORAM) e IPHAN (Instituto do Patrimônio Histórico e Artístico Nacional) com o intuito de salvaguardar as casas que estão sendo violadas em seus direitos humanos fundamentais, pois há uma série de exigências absurdas (BRASIL, 2017). Por exemplo, em relação ao barulho (poluição sonora), o isolamento acústico é totalmente impossível, pois o som dos atabaques é elemento fundamental do culto, responsável pela comunicação espiritual entre o "mundo carnal" e o "mundo espiritual”. Em outras palavras, isolar acusticamente as casas de axé, casas de santo é criar "embaraços" para o funcionamento dos cultos afro-brasileiros, em total violação ao art. 19 da Constituição da República de $1988^{3}$.

Por isso, a Ação Civil Pública pede a declaração de inconstitucionalidade da Lei Complementar n 479/2013 (BRASIL, 2015), a qual, impõe limitação de horário de

\footnotetext{
${ }^{3}$ Art. 19. É vedado à União, aos Estados, ao Distrito Federal e aos Municípios:

I - estabelecer cultos religiosos ou igrejas, subvencioná-los, embaraçar-lhes o funcionamento ou manter com eles ou seus representantes relações de dependência ou aliança, ressalvada, na forma da lei, a colaboração de interesse público;

II - recusar fé aos documentos públicos;

III - criar distinções entre brasileiros ou preferências entre si ( BRASIL,1988).
} 
funcionamento aos "locais destinados a manifestação da cultura religiosa afrobrasileira". Conforme assegurado constitucionalmente, o funcionamento dos templos religiosos não pode ser limitado pelo legislador. Confunde-se o funcionamento com rituais específicos que, estes sim, poderiam sofrer limitação. Há diversas atividades nos templos que não envolvem festividades e batuque, ocorrendo às vezes por dias ininterruptos e que, por óbvio, não podem se sujeitar à regra municipal.

Nesse sentido, mesmo nos anos 2000 vivenciamos ataques a ritualística dos povos de terreiro. Lembrando que o bater do atabaque é elemento indispensável para o culto. A interferência do Poder Público, principalmente através de Polícia Militar do Estado, que estaria muitas vezes atuando para fazer cessar as cerimónias religiosas, é verdadeiro desrespeito ao direito fundamental à liberdade de crença. $\mathrm{O}$ incorreto enquadramento dos templos religiosos como "comércio em geral" acaba por não permitir que usufruam da especial previsão do art. $8^{\circ}$, inc. Vll, da LCM no 003/99 (BRASIL, 2015), que possibilita volume de até $65 \mathrm{~dB}$. A própria FLORAM admite que lavra as multas sem medição dos decibéis, uma vez que os terreiros não teriam uma regulamentação acústica específica (DESACATO, 2018).

Felizmente, a $6^{\mathrm{a}}$ Vara Federal de Florianópolis declarou a inconstitucionalidade da Lei Complementar municipal 479/2013. A juíza Marjôrie Cristina Freiberger a norma possui "natureza discriminatória" por limitar apenas o funcionamento dos centros de umbanda, e não das manifestações religiosas como um todo. São 109 terreiros na cidade que serão beneficiados pela decisão judicial. O levantamento, feito pela Universidade Federal de Santa Catarina em parceria com o Instituto do Patrimônio Histórico e Artístico Nacional (Iphan), faz parte do estudo antropológico Territórios do Axé, iniciado em julho de 2016. Em dezembro daquele ano, a juíza Marjôrie Cristina Freiberger reafirmou a importância da conclusão da pesquisa para o julgamento da ação judicial em curso. Os dados colhidos apontam que 80,47\% das 210 casas entrevistadas já sofreram alguma forma de intolerância. Além de Florianópolis, foram levados em conta os centros em Biguaçu, Palhoça e São José.

De acordo com Vanda Pinedo, representante do Fórum de Religiões de Matriz Africana, "muitos terreiros não têm medição [sonora] e foram abordados às $8 \mathrm{~h}, 9 \mathrm{~h}$ da noite. Todas as outras religiões professam suas fés, fazem caminhadas, tocam seus sinos, tocam instrumentos de metais, e nós temos instrumentos legítimos.” Ela ressalta o 
tambor como um elemento essencial dos cultos afro-brasileiros. "Retirar o tambor de nossa prática (...) é refutar a fundamentação e a sobrevivência da nossa religião".

A juíza Marjôrie Freiberger determinou o fim da limitação de funcionamento por horário e o fim da exigência para Certidões de Tratamento Acústico, que impeçam a realização de cerimônias religiosas. A Certidão só pode ser demandada se os decibéis previstos no artigo $8^{\circ}$ da Lei 003/1999 forem excedidos, verificação que deve ser realizada por meio de medição efetiva. A medição também é imprescindível para qualquer eventual sanção devido ao excesso de ruído. Além disso, a juíza afastou a exigência de alvarás com os mesmos requisitos de bares e similares e reafirmou o direito de os centros religiosos utilizarem velas e incensos durante os cultos.

A orientação proposta pelas notas técnicas, recomendações e pela decisão judicial de Florianópolis são relevantes para que as abordagens policiais e dos agende públicos nos terreiros ocorra de forma respeitosa e em observância aos Direitos Humanos. As leis não devem ser aplicadas sem considerar as especificidades dessas comunidades. Como diz Débora Duprat, a Constituição da Republica de 1988 reconhece a plurietnicidade do Estado Brasileiro e, portanto, os terreiros devem ser reconhecidos como espaços da diferença, locus étnico e cultural da formação e manutenção da ancestralidade africana no Brasil, devendo suas práticas tradicionais serem consideradas e ponderadas na aplicação de normas restritivas de direitos.

Em razão disso, há de se estimular o reconhecimento e o respeito mútuo entre as diversas culturas que coexistem em nossa sociedade. $\mathrm{O}$ direito à própria identidade e ao acesso aos modos de viver, de se expressar e de se portar diante do mundo, de acordo com essa identidade, devem sempre ser levados em consideração pelo Estado, incumbido de zelar pela preservação das minorias e sua identidade cultural.

De acordo com a Convenção para Salvaguarda do Patrimônio Cultural Imaterial, os instrumentos e as expressões, assim como as práticas, objetos e lugares a eles associados, integram esse patrimônio imaterial, o que demanda uma ação do Estado não apenas para protegê-los, mas também para promover sua valorização e sua transmissão. As minorias étnicas e religiosas têm o direito à preservação de sua herança cultural mediante a proteção de cada um dos aspectos que integram sua identidade e sua memória ancestral.

A partir dessa perspectiva, cabe, portanto, ao Estado brasileiro o dever de preservá-los. É importante lembrar da Declaração sobre a Eliminação de todas as 
formas de Intolerância e Discriminação Fundadas na Religião ou nas Convicções, para observar que toda pessoa tem o direito de manifestar sua religião através de cultos e do uso de objetos litúrgicos, sendo que qualquer discriminação entre as pessoas por motivo de religião constitui violação aos direitos humanos e às garantias fundamentais. Sendo assim, há um direito de preservação dessas manifestações religiosas e culturais, a partir da continuidade de suas tradições e de acordo com as visões do mundo herdadas há séculos. É o que se denomina de herança cultural.

Nessa linha de entendimento, o Estado não deve analisar a questão utilizando "lentes" de uma cultura ou religião predominante, mas sim através da ótica da pluralidade e do respeito pela diversidade. Com esse pensar, deve-se partir da premissa de que toda intervenção nesse patrimônio cultural deve procurar integrar, em seu processo de decisão, o sentimento de pertencimento que emana do grupo humano que sofrerá as consequências em caso de intromissão.

O Estado Democrático, assim, exige que normas e atos administrativos que não sejam capturados ou utilizados por ideologias ou preferências religiosas, a fim de distribuir benesses para uns enquanto cria dificuldades burocráticas para outros. De fato não é raro verificar a existência de atos que, a pretexto de tutelar a "ordem pública" ou a "paz pública", inviabilizam a prática de direitos das minorias ou as empurram para guetos e rincões mais afastados. Nesse sentido, normas penais em branco ou com conceitos jurídicos indeterminados podem constituir campos férteis para a arbitrariedade (BAHIA,2016).

Portanto, para que se possa distribuir justiça, equidade e eficiência, toda decisão administrativa deve guardar os princípios da razoabilidade e da proporcionalidade, assegurando que grupos minoritários não se vejam impedidos de manifestar suas crenças religiosas e de ter acesso à sua própria cultura, por meio do uso de seus objetos litúrgicos. Em outros termos, não se pode pretender impor um padrão de vida a partir de limitações exacerbadas que possam sufocar por completo o exercício de direitos fundamentais inerentes à dignidade da pessoa humana.

Não se quer dizer que práticas tradicionais estejam ou sejam imunes à lei, mas sim que precisam de uma análise mais aprofundada, que considere os legados e valores culturais colocados em risco, e que não podem ser aferidos nos parâmetros cartesiano.

O Poder Público pode impor restrições ao exercício de determinado direito, mas desde que isso não conduza ao patamar de anulá-lo ou descaracterizá-lo. Por isso que, diante do caso concreto, é necessária uma análise mais ampla e acurada dos impactos 
envolvendo os rituais religiosos, para que se verifique se há, ou não, afronta à liberdade de culto. Do contrário, o sistema de justiça continuará a adotar posturas reticentes e tímidas diante de situações complexas que afetam diretamente as religiões de matriz africana e as suas práticas. É necessário que o "rezado baixo de Xangô" assuma outros contornos, que os sons das palmas sejam somados com os sons dos atabaques e que se permita aos povos de terreiro a real efetividade dos seus direitos.

\section{Referências Bibliográficas}

ARAUJO, Mauricio de Azevedo. Do combate ao racismo à afirmação da alteridade negra: as religiões de matriz africana e a luta por reconhecimento jurídico repensando a tolerância e a liberdade religiosa em uma sociedade multicultural. 2007. 120 f. Dissertação (Mestrado em Direito) - Universidade de Brasília, Brasília, 2007.

BAHIA. Ministério Público da Bahia. Nota técnica $n^{\circ} 02$ de 16 de novembro de 2016. Disponível em: <https://www.mpba.mp.br/content/nota-t\%C3\%A9cnica-n\%C2\%BA02-de-16-de-novembro-de-2016>. Acesso em: 15 maio 2018.

BRASIL. Congresso Nacional. Constituição da República Federativa do Brasil promulgada em 5 de outubro de 1988. Disponível em: <http://www.planalto.gov.br/ccivil_03/Constituicao/Constituicao.htm>. Acesso em: 5 fev. 2018.

BRASIL. Congresso Nacional. Decreto $n^{\circ}$ 7.037, de 21 de dezembro de 2009. Disponível em: <http://www.planalto.gov.br/ccivil_03/_Ato20072010/2009/Decreto/D7037.htm>. Acesso em: 19 set. 2018.

BRASIL. Congresso Nacional. Lei $n^{o}$ 12.288, de 20 de julho de 2010. Disponível em: <http://www.planalto.gov.br/ccivil_03/_Ato2007-2010/2010/Lei/L12288.htm>. Acesso em: 19 set. 2018.

BRASIL. Tribunal Regional Federal (4. Região). Ação civil pública $\mathrm{n}^{\circ}$ 502359245.2015.4.04.7200. 2015. Disponível em: <https://www2.trf4.jus.br/trf4/controlador.php?acao=consulta_processual_resultado_pe squisa\&selForma=NU\&txtValor $=50235924520154047200 \&$ chkMostrarBaixados $=\&$ tod asfases $=\&$ todosvalores $=\&$ todaspartes $=\&$ txtDataFase $=\&$ selOrigem $=$ SC $\&$ sistema $=\&$ hdn RefId=\&txtPalavraGerada=\&txtChave=>. Acesso em: 19 set. 2018.

BRASIL. Ministério das Mulheres, da Igualdade Racial, da Juventude e dos Direitos Humanos. Secretaria Especial de Direitos Humanos. Relatório sobre intolerância e violência religiosa no Brasil (2011 - 2015): resultados preliminares. FONSECA, Alexandre Brasil; ADAD, Clara Jane Costa (Org.). Brasília: Secretaria Especial de Direitos Humanos, 2016.

BRASIL. Defensoria Pública da União. Garantias para cultos de religiões de matriz africana são discutidas em SC. 2017. Disponível em: <http://www.dpu.def.br/noticias- 
santa-catarina/158-noticias-sc-slideshow/36864-garantias-para-cultos-de-religioes-dematriz-africana-sao-discutidas-em-sc>. Acesso: 15 maio 2018.

CAVALCANTI, Bruno Cesar. O antropólogo Bruno César e o Historiador Luiz Sávio de Almeida falam sobre o Quebra de Xangô. [Programa de TV exibido em 02/11/2012]. 2012.

DESACATO. FLORAM multa terreiros de Umbanda por barulho. 2015. Disponível em: <http://desacato.info/floram-multa-terreiros-de-umbanda-por-barulho/>. Acesso: 15 maio 2018.

FERNANDES, Nathália Vince Esgalha; ADAD, Clara Jane. Costa. Intolerância ou Racismo Religioso: Discriminação e Violência contra As Religiões De Matriz Africana. Revista Intolerância Religiosa, Rio de Janeiro, v. 2, n. 1, p. 1-17, 2017.

GUIMARÃES, Andréa Letícia Carvalho. ÈTÓ FÚN ÀWÓN TÓ YÀTÒ: análise do I Plano Nacional de inclusão dos Povos e Comunidades Tradicionais de Matriz Africana a partir dos processos de reconstrução da identidade do sujeito constitucional. 2014. 194 f. Dissertação (Mestrado em Direito) - Universidade de Brasília, Brasília, 2014.

HALL, Stuart. Da Diáspora: Identidades e mediações culturais. Tradução de Adelaine La Guardiã Resende et al. Belo Horizonte: Editora UFMG, 2003.

MINAS GERAIS. Ministério Público do Estado de Minas Gerais. Nota técnica CAODH $n^{o} \quad 001 / 2016 . \quad$ Disponível em: <http://www.direito.mppr.mp.br/arquivos/File/Igualdade_Racial/Notatecnica0012016.p df $>$. Acesso em: 19 set. 2018.

MINISTÉRIO PÚBLICO. Conselho Nacional Do Ministério Público. Resolução $n^{\circ} 23$, de 17 setembro de 2007. Disponível em: <http://www.cnmp.mp.br/portal/atos-enormas/norma/501>. Acesso em: 19 set. 2018.

MINISTÉRIO PÚBLICO. Conselho Nacional Do Ministério Público. $20^{\mathrm{a}}$ Sessão Ordinária de 2017. Disponível em:

<http://www.cnmp.mp.br/portal/images/sessoes_plenario/PAUTA-CONSELHEIROS--20-Sesso-Ordinria.Portal.pdf>. Acesso em: 19 set. 2018.

NASCIMENTO, Wanderson Flor do. Sobre os candomblés como modo de vida: imagens filosóficas entre Áfricas e Brasis. Ensaios Filosóficos, Rio de Janeiro, v. 13, p. 153-170, 2016. Disponível em:

<http://www.ensaiosfilosoficos.com.br/Artigos/Artigo13/11_NASCIMENTO_Ensaios_ Filosoficos_Volume_XIII.pdf $>$. Acesso em: 15 maio 2018.

PARANÁ. Ministério Público do Paraná. Recomendação Conjunta $n^{o}$ 01/2018. Disponível em: <http://www.urbanismo.mppr.mp.br/arquivos/File/rec_adm_01_2018.pdf>. Acesso em: 15 ago. 2018. 
RAFAEL, Ulisses Neves. Xangô rezado baixo: um estudo da perseguição aos terreiros de Alagoas em 1912. 2004. 266 f. Tese (Doutorado em Sociologia e Antropologia) UFRJ - IFCS: Programa de Pós-Graduação em Sociologia e Antropologia, Rio de Janeiro, 2004.

SANTOS, Edmar Ferreira. Sambas, batuques e candomblés em Cachoeira-Bahia: a construção ideológica da cidade do feitiço. 2007. 214 f. Dissertação (Mestrado em Estudos Étnicos e Africanos) - Universidade Federal da Bahia, Salvador, 2007.

SIMÕES, Lucas. Batuque na cozinha, sinhá não quer. 2017. Disponível em: <http://www.obeltrano.com.br/portfolio/batuque-na-cozinha-sinha-nao-quer/>. Acesso em: 19 set. 2018.

VIDA, Samuel. A constitucionalidade das políticas públicas de combate à discriminação racial enquanto dever do Estado. Revista Cepaia: realidade AfroIndígenas, Salvador, n. X, 1999.

Recebido em: 10/12/2019

Aceito em: 20/12/2019 